\title{
Effect of limestone and granite coarse aggregate on drying shrinkage of a concrete
}

\author{
Piotr Woyciechowski ${ }^{1, *}$, Karol Chilmon $^{1}$, and Joanna Julia Sokołowska ${ }^{1}$ \\ ${ }^{1}$ Department of Building Materials Engineering, Warsaw University of Technology, 00-637 Warsaw, \\ Poland
}

\begin{abstract}
In this paper the effect of limestone and granite aggregate on drying shrinkage of a concrete is investigated. Mixes containing limestone and granite with different $\mathrm{D}_{\max }$ and cement paste volume were tested. A two level, full factorial experiment with three independent factors was conducted which allowed not only to determine the influence of every single factor itself but also potential interactions between them. Measurements of shrinkage were performed up to 98 days after demolding on the beams $(10 \times 10 \times 50 \mathrm{~cm})$, in accordance with the procedure from polish standard PN-84/B-06714/23 (Amsler's method). The multivariate analysis of variances (MANOVA) was used for the statistical analysis of the results. The obtained results confirm that the cement paste volume has a decisive influence on a drying shrinkage of a concrete. However statistical analysis showed that with the assumed variability, either the $\mathrm{D}_{\max }$ or type of coarse aggregate has no significant influence on drying shrinkage, still those parameters may potentially be crucial in some cases. A statistically significant interaction between $D_{\max }$ and type of aggregate has been found. Furthermore the results of drying shrinkage measurements were compared with estimation results from Bażant-Baweja B3 Model and Eurocode 2. The comparison shows that B3 Model provided more accurate results than Eurocode 2.
\end{abstract}

\section{Introduction}

Drying shrinkage plays a significant role in concrete. It causes the vast majority of the total shrinkage strain in concrete [1]. This process, which is caused by migration of water molecules from inside of the concrete, can last up to several decades. The water molecules separate from the surface or from the space between the particles of C-S-H phase, the thickness of the diffusion layer decreases, which is followed by contraction of the cement grains, whereupon the material shrinks. The intensity of the phenomenon depends on many factors, among which the most important are: air relative humidity $(\mathrm{RH})$, water-cement ratio $(\mathrm{w} / \mathrm{c})$, cement paste content (by volume), concrete element surface to volume ratio, time and type of curing, concrete pore structure and mechanical properties of concrete.

In general, aggregate enables to reduce the shrinkage strain in concrete. This is due to the reduction of the cement paste content in the concrete mix and by limiting the

* Corresponding author: p.woyciechowski@,il.pw.edu.pl 
deformation of the cement matrix (stiffening of the concrete structure). The degree of shrinkage deformation limit depends mainly on the geometrical properties of the aggregate and the geomechanical properties of the rock from which aggregate was obtained. The shape of the grains, roughness, size, elasticity modulus of the rock, porosity, chemical composition - all these properties theoretically affect the deformation properties of the concrete which - in a practical way - is determined by the value of elasticity modulus obtained during the compressive strength test. Therefore, it seems reasonable to investigate which of these characteristics in a practical way can be used at the stage of designing the concrete aggregate mix granulation that prevent or limit the shrinkage of concrete. This paper presents the results of research conducted on determining the crucial properties of coarse aggregate that influence the drying shrinkage of concrete.

\section{Experimental studies}

\subsection{Research design}

The study was performed according to two-level research design of three independent variables: cement paste content (by volume), maximal size (diameter) of coarse aggregate grains and the type of aggregate. Based on the design eight concrete compositions were designed (Fig. 1). As constants adopted: sand content (\%), water-cement ratio (kg/kg), and a method of forming, maintenance and storage of specimens.

Aggregate was characterized using results of tests performed earlier by Pinińska [2,3] the analyzed property was average static modulus of rock. The value of the modulus was determined during compressive strength test performed on the core specimens of size $5 \mathrm{~cm}$ $\mathrm{x} 5 \mathrm{~cm}$. The test was done assuming the constant increase of circumferential strain compressed specimens. The value of the modulus was calculated on the basis on the straight sections of pre-critical part of stress-strain curves. Because of the different research method, elastic modulus determined using this method cannot be related directly to the secant modulus of elasticity of concrete, and therefore this value is used only to compare the characteristics of various types of aggregate applied into concrete mix in the presented study.

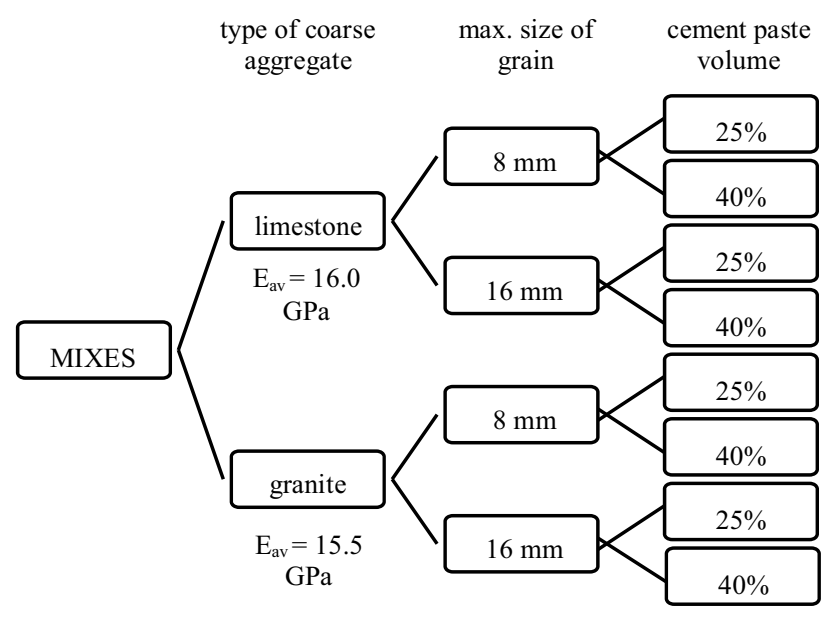

Fig. 1. A two level full-factorial research design used in experimental studies. 


\subsection{Materials}

The cement used to prepare concrete tested in the study was Portland cement CEM I 42,5R, the applied aggregate was river sand and two fractions of gravel: $2 / 8 \mathrm{~mm}$ and 2/16 $\mathrm{mm}$. The coarse aggregate was crushed politic limestone (source: Sitkówka-Nowiny, Świętokrzyskie Mountains) and crushed granite (source: Strzegom-Sobótka, Lower Silesian region). The main mechanical properties of applied aggregates are given in table 1.

Table 1. Mechanical properties of rocks from which coarse aggregate used in this studies was obtained $[2,3]$.

\begin{tabular}{|c|c|c|}
\hline characteristic & $\begin{array}{c}\text { granite } \\
\text { min- max } \\
\text { (average) }\end{array}$ & $\begin{array}{c}\text { politic limestone } \\
\text { min - max } \\
\text { (average) }\end{array}$ \\
\hline $\begin{array}{c}\text { elastic modulus (static), } \\
\mathrm{GPa}\end{array}$ & $\begin{array}{c}9.6-23.8 \\
(15.5)\end{array}$ & $\begin{array}{c}13.4-17.8 \\
(16.0)\end{array}$ \\
\hline $\begin{array}{c}\text { compressive strength, } \\
\mathrm{MPa}\end{array}$ & $\begin{array}{c}60.7-174.4 \\
(120.8)\end{array}$ & $\begin{array}{c}127.0-218.0 \\
(181.0)\end{array}$ \\
\hline
\end{tabular}

\subsection{Concrete composition}

In the table 2 one can find the quantitative compositions of concretes tested in the presented study. The compositions were designed according to the statistical design described in the paragraph 2.1 .

Table 2. Compositions of tested concretes.

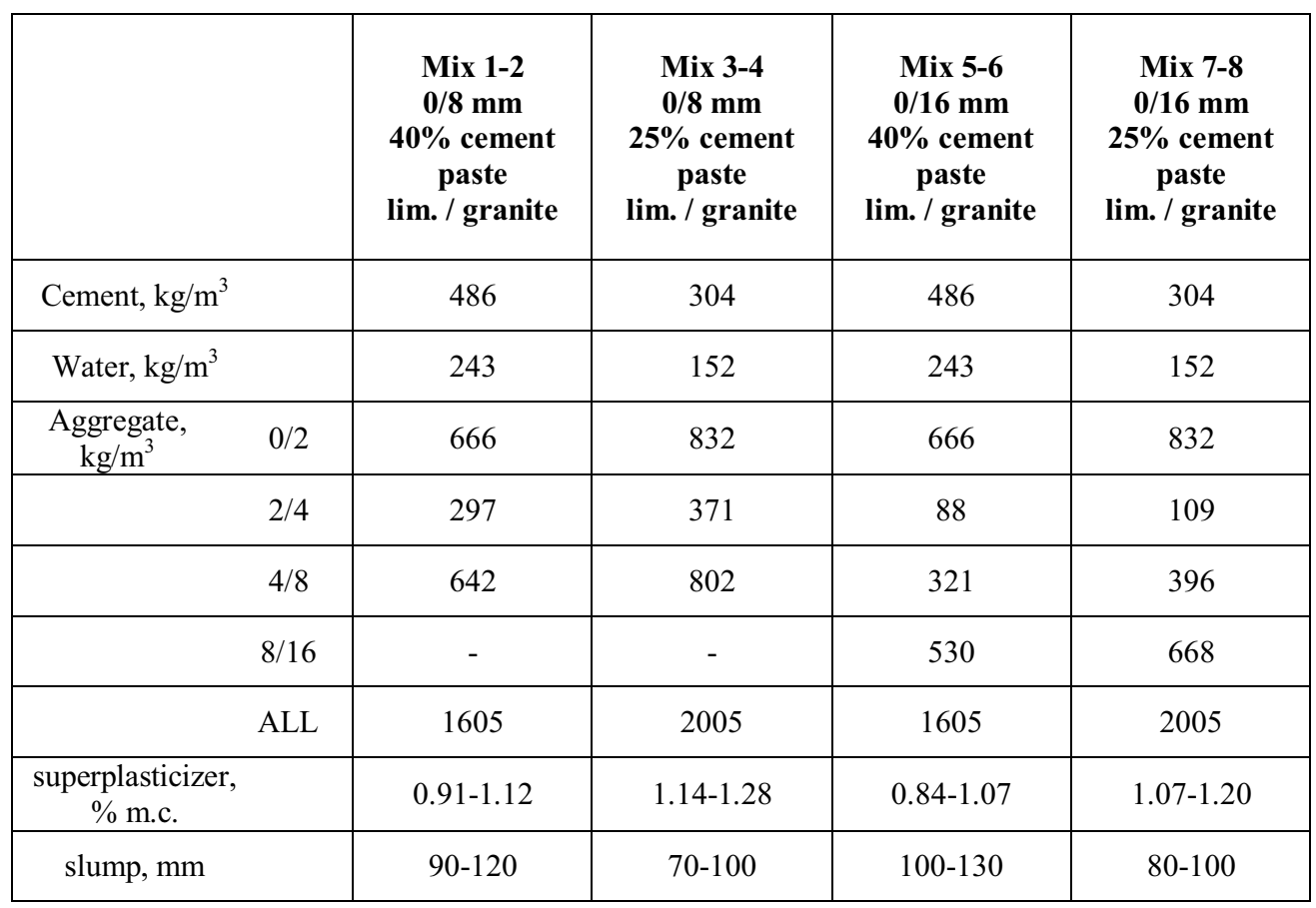




\subsection{Drying shrinkage measurements}

The shrinkage was tested according to Amsler method; the tested specimens were in the shape of beams of size 100x100x500 mm with special metal grips located on the edges that enabled measurements of the length change in the Amsler apparatus (Fig. 2a) in comparison to metal calibration element (Fig. 2b).

a)

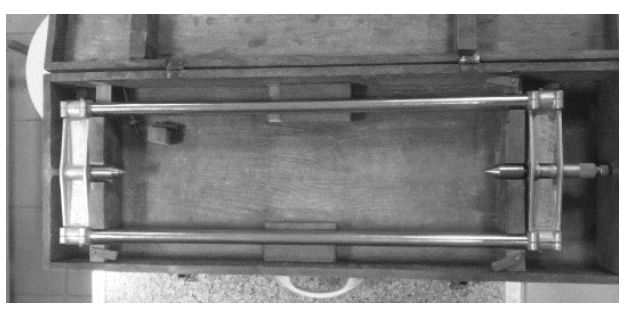

b)

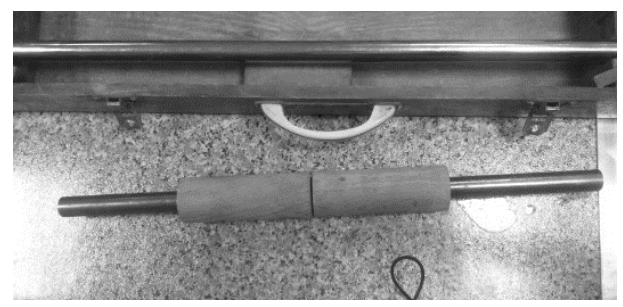

Fig. 2. Amsler's test apparatus a) frame with micrometrical screw on its end b) steel calibration element.

The specimens were cured for $24 \mathrm{~h}$ in the laboratory conditions in the molds (covered with foil), then after remolding the first shrinkage measurement was performed - the value was considered to be the reference point. Next, the beams are stored for the whole period in a temperature range of $18-22^{\circ} \mathrm{C}$ and average relative humidity of $80 \%$ within the first 28 days, and during the next 70 days - in relative humidity of $50 \%$. Such humidity curing conditions enabled to simulate the variation of relative humidity registered during the year in the central Poland area. Measurements of shrinkage were made in successive time intervals ranging from 1 to 98 days of curing.

\subsection{Effect of variables on concrete drying shrinkage}

\subsubsection{Main effects}

For the statistical analysis of the significance of the impact of the volumetric content of the cement paste in the concrete mix, the type of aggregate and the maximum aggregate size the results of shrinkage test obtained after 98 days were used. These values were subjected to multivariate analysis of variance (MANOVA) by which it was possible to determine separately the main variables influence and determine the interactions. The statistical analysis was performed with statistical significance of $\alpha=0.05$.

Preliminary analysis showed that the distribution of the shrinkage values characterized by a distinct scattering data on both sides of the median (Fig. 3a). Among the data prevailed values located around the three vertices (Fig. 3b), which indicated a strong influence of at least one variable. 
a)

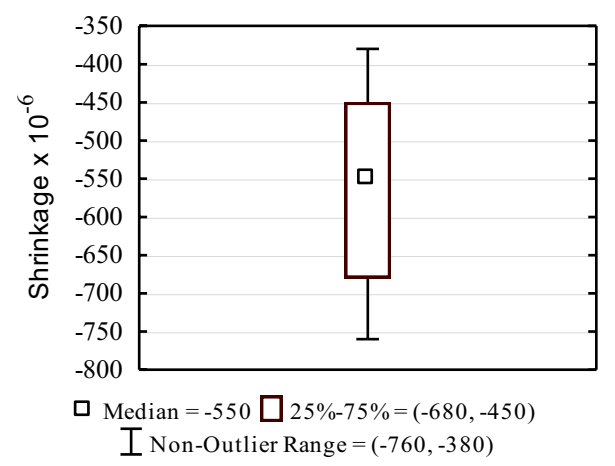

b)

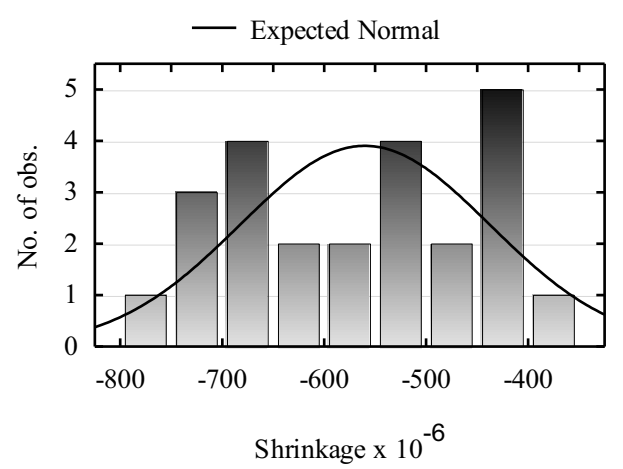

Fig. 3. Basic statistics for obtained data a) Box-Whisker plot, b) histogram.

Before performing the multi-variance analysis, authors examined the conditions for its application. Normality distribution was confirmed using the K-S test corrected for small populations (the null hypothesis accepted with $\mathrm{p}=0.2>0.05$ ) and Shapiro-Wilk (the null hypothesis accepted with $\mathrm{p}=0.6>0.05$ ). The homogeneity of variance for all groups was confirmed by the Leven's test.

As a result of multi-variance analysis of the test results it was showed that the strongest influence on the shrinkage value presents the content (by volume) of the cement paste in the concrete mix (see Fig. 4a and Table 3). At the same time it was found that neither the change of the aggregate type - i.e. limestone to granite (Fig. 4b), nor the change of maximal size of aggregate (expressed by maximal diameter of the aggregate grain, $D_{\max }$ ) from $8 \mathrm{~mm}$ to $16 \mathrm{~mm}$ (Fig. $4 \mathrm{c}$ ) do not affect significantly the value of shrinkage (Table 3).
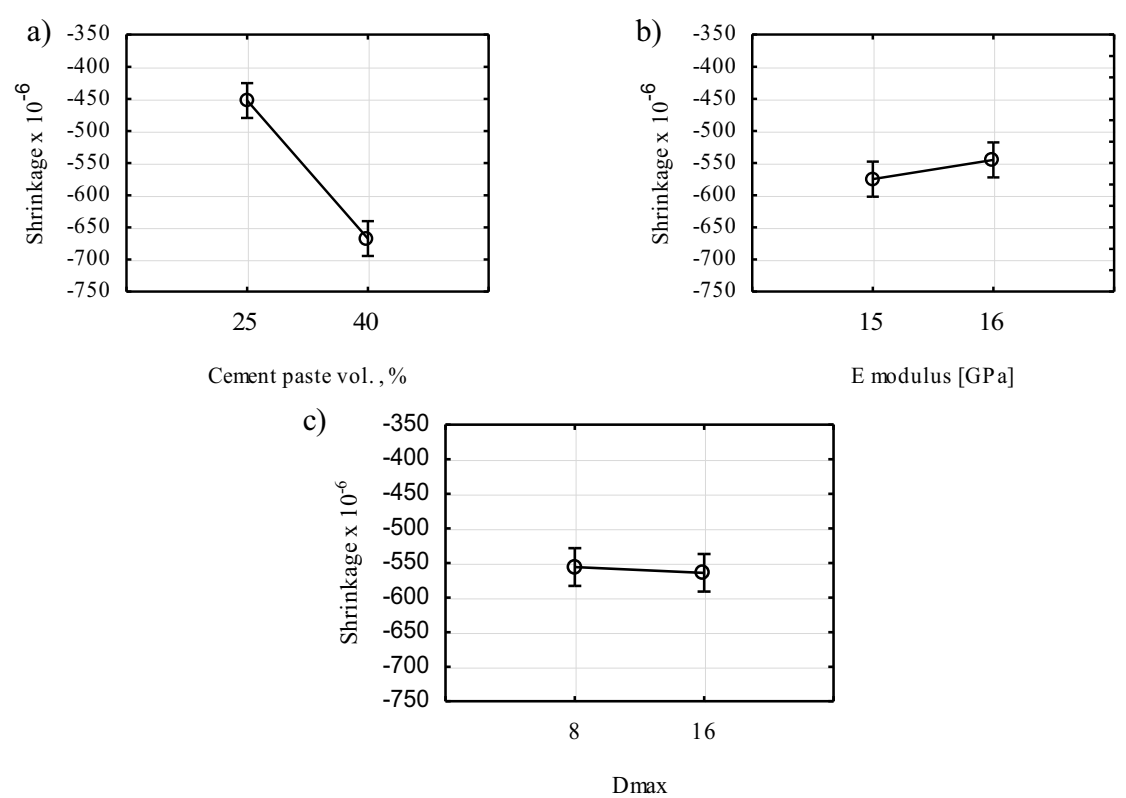

Fig. 4. Relation between variables and shrinkage a) cement paste content (by volume) vs. shrinkage b) E modulus vs. shrinkage (15 GPa limestone, $16 \mathrm{GPa}$ granite c) maximal aggregate size, $\mathrm{D}_{\max }$ vs. Shrinkage. 
Table 3. MANOVA results for main effects (MS - Mean Square, F - F test statistic, p - probability used to determine statistical significance, significance level $\alpha=0,05$ ).

\begin{tabular}{|c|c|c|c|c|}
\hline Effect & MS & F & p-value & $\begin{array}{c}\text { observed } \\
\text { power }\end{array}$ \\
\hline Cement paste vol. & 277350 & 140.73 & $<10^{-6}$ & 1.00 \\
\hline E modulus & 5400 & 2.74 & 0.12 & 0.34 \\
\hline $\mathrm{D}_{\max }$ & 417 & 0.211 & 0.65 & 0.07 \\
\hline
\end{tabular}

\subsubsection{Interactions}

There was observed one statistically significant interaction - the interaction between the type of aggregate and the maximum diameter of the aggregate (Table 4). The shrinkage deformation value decreased by $5 \%$ when the maximum grain size of $8 \mathrm{~mm}$ was changed to $16 \mathrm{~mm}$ in the case of crushed granite and increased by $11 \%$ in case of limestone aggregate.

Table 4. MANOVA results for interactions (MS - Mean Square, F - F test statistic, p - probability used to determine statistical significance, significance level $\alpha=0.05$ ).

\begin{tabular}{|c|c|c|c|c|}
\hline Effect & MS & F & p & $\begin{array}{c}\text { observed } \\
\text { power }\end{array}$ \\
\hline $\begin{array}{c}\text { Cement paste vol. } \\
\text { x E modulus }\end{array}$ & 6017 & 3.05 & 0.10 & 0.38 \\
\hline E modulus x D max $_{1}$ & 16017 & 8.13 & 0.01 & 0.76 \\
\hline $\begin{array}{c}\text { Cement paste vol. } \\
\text { x D } D_{\max }\end{array}$ & 8067 & 4.093 & 0.06 & 0.48 \\
\hline $\begin{array}{c}\text { Cement paste vol. } \\
\text { x } \mathrm{D}_{\max } \times \text { E modulus }\end{array}$ & 600 & 0.304 & 0.59 & 0.08 \\
\hline
\end{tabular}

\subsection{Drying shrinkage in time}

The shrinkage development registered during the period of 98 days in all considered cases were similar. The difference was observed when analyzing the expansion of concrete with various aggregates the noticeable expansion was noted during first days of curing in case of concrete with limestone aggregate of size up to $8 \mathrm{~mm}$ and concrete with granite aggregate of size up to $16 \mathrm{~mm}$. This was due to the absorption of water by the aggregate and then water was gradually released back into the concrete. The cement matrix because of lack of water demanded for hydration in the early phase of curing absorbed water from the humid environment causing extension of concrete. The shrinkage increased rapidly during first 1014 days, and then the rate of process slowed down. Lowering the relative humidity after 28 days (from $\mathrm{RH}=80 \%$ to $50 \%$ ) did not significantly affect the development of shrinkage over time.

The obtained results were compared with the results of the estimated shrinkage values with use of two theoretical models: B3 Bażant-Bawej model [4] and the model given in standard EN 1992-1-1 [1] used by concrete structures designers (Fig. 4). The calculations 
assume an average relative humidity of $65 \%$ test conditions and takes into account the compressive strength obtained after 28 days of curing (data for concrete mix of $40 \%$ cement paste content - concrete fulfilling the requirements of concrete compressive class $\mathrm{C} 30 / 37$, and of $25 \%$ cement paste content - concrete fulfilling the requirements of class C20/25).

a)

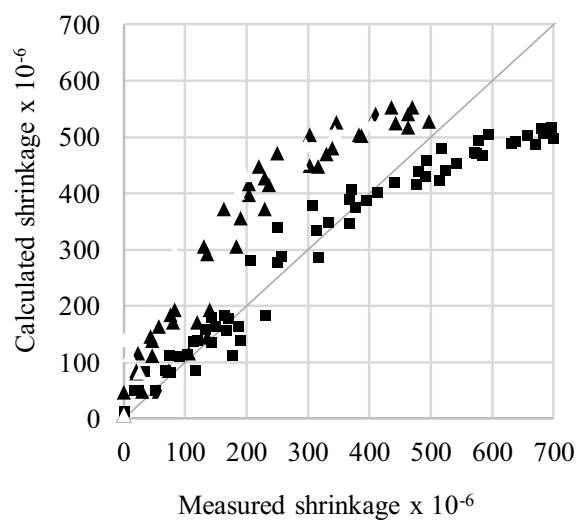

- $40 \%$ cement paste \ $25 \%$ cement paste b)

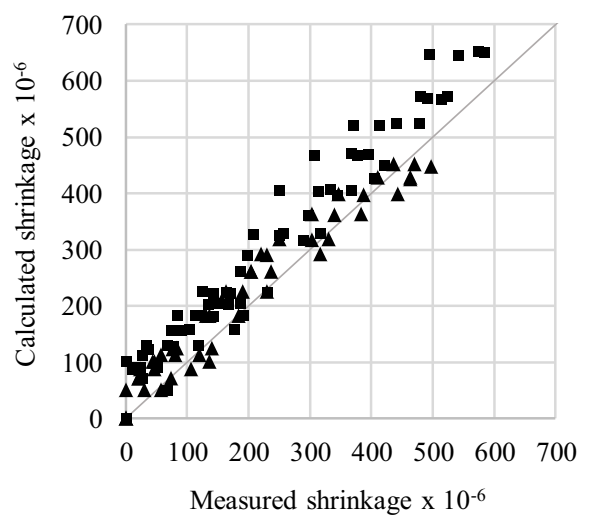

- $40 \%$ cement paste $\quad \Delta 25 \%$ cement paste

Fig. 4. Theoretical models vs. obtained data a) Eurocode 2 vs data b) Bażant-Baweja B3 Model vs data.

\section{Conclusions}

The content of cement paste in the concrete plays a decisive role in shaping the drying shrinkage. Although the change of the maximum grain diameter of $8 \mathrm{~mm}$ to $16 \mathrm{~mm}$ has not influenced the shrinkage deformation value significantly, it has caused different course of shrinkage of concrete with limestone and granite aggregate. This could be related to different adhesion between those two aggregates and cement matrix. Calcium carbonate present in the limestone reacts with the calcium aluminates in Portland cement. As a product of the reaction, the crystals of calcium carbo-aluminate $\left(\mathrm{C}_{3} \mathrm{ACaCO}_{3} \mathrm{H}_{11}\right)$ appear. They clearly improve the mechanical properties of the contact layer between cement matrix and aggregate. Meanwhile the adhesion between cement matrix and granite aggregate is purely mechanical.

However the type of the aggregate has not affected significantly the drying shrinkage value. Concrete with limestone aggregate showed a slightly higher shrinkage than the one with granite aggregate. This could be due to a greater diversity of deformation properties of aggregates than the average values accepted in the study (in case of granite one can clearly find higher range of variation of Young's modulus than in case of limestone). In order to verify this hypothesis there should be determined the secant modulus of elasticity of concrete. Use of aggregates with more diverse characteristics of deformation properties may cause more significant influence of this variable.

It was proved, that lowering the relative humidity from $80 \%$ to $50 \%$ after 28 days did not result in observable change in the growth rate of shrinkage deformation of tested concretes. Albeit preserving the relatively high relative humidity during the first period, the shrinkage grew rapidly. 
Comparing shrinkage measurements results obtained in the experiment with theoretical models shows that B3 Bażant-Bawej model provides a more accurate estimation of shrinkage deformation than Eurocode 2 model. This is due to a greater number of variables taken into account in model B2. In the case of Eurocode 2 model occurred noticeable underestimation of shrinkage deformation of concrete with a higher content of cement paste, especially in the long term, and underestimation for concrete with an average content of cement. In turn, the model B3 overestimated results in case of concrete with higher cement content. Both models deliver better results in case of estimating shorter periods.

\section{References}

1. EN 1992-1-1:2004 - Eurocode 2: Design of concrete structures - Part 1-1: General rules and rules for buildings (2004)

2. J. Pinińska, Właściwości wytrzymatościowe i odkształceniowe skat. Część II. Skały magmowe, osadowe i metamorficzne regionu Sudetów. Katalog. (Wydział Geologii Uniwersytetu Warszawskiego, Warszawa, 1997)

3. J. Pinińska, Wlaściwości wytrzymałościowe i odkształceniowe skat. Czesść I. Skaty osadowe regionu świętokrzyskiego. Katalog. (Wydział Geologii Uniwersytetu Warszawskiego, Warszawa, 1994)

4. Z.P. Bażant, S. Baweja, ACI Special Publications (2000) 